\title{
Temporal-Spatial Variation Characteristics of Soil Erosion in the Pisha Sandstone Area, Loess Plateau, China
}

\author{
Yang $\mathrm{Li}^{1-3}$, Zhixiang $\mathrm{Xie}^{1-3}$, Yaochen Qin ${ }^{1-3 *}$, Yingying Sun ${ }^{1}$ \\ ${ }^{1}$ College of Environment and Planning, Henan University, Kaifeng, China \\ ${ }^{2}$ Key Laboratory of Geospatial Technology for Middle and Lower Yellow River Region, Kaifeng, China \\ ${ }^{3}$ Collaborative Innovation Center of Urban-Rural Coordinated Development, Zhengzhou, China
}

Received: 15 March 2018

Accepted: 5 July 2018

\begin{abstract}
Soil erosion in the Pisha sandstone area of the Loess Plateau in China has become a severe environment issue that has raised concerns globally. The projects of ecological restoration in this area and their impact on soil erosion have been analyzed using the unmanned aerial vehicle remote sensing system (UAVRSS) and the revised universal soil loss equation (RUSLE) in the Two-Tiger Valley Basin in 2013 and 2015. Our findings show that:

1) The volume of soil erosion and average soil erosion modulus decreased from $126.24 \mathrm{tyear}^{-1}$ and $6465.295 \mathrm{t} \mathrm{km}^{-2}$ year $^{-1}$ to $114.7 \mathrm{t}_{\text {year-1 }}$ and $6333.19 \mathrm{t} \mathrm{km}^{-2}$ year ${ }^{-1}$ between 2013 and 2015, respectively.

2) Spatial-temporal variations of soil erosion are extremely significant. All erosion grades recorded different degrees of decline across the study period, except for the level of severe erosion.

3) There is a significant positive correlation between slope degree and soil erosion. When the slope degree was $<5^{\circ}$, the soil erosion modulus was $51.355 \mathrm{t} \mathrm{km}^{-2}$ year $^{-1}$, accounting for only $0.87 \%$ of total erosion in this area. When the slope degree was $>35^{\circ}$, the soil erosion modulus attained $2574.413 \mathrm{t}$ $\mathrm{km}^{-2}$ year $^{-1}$, and the erosion amount accounted for $43.52 \%$ of total erosion. Although anti-erosion and the promotion of plant growth measures have achieved noticeable ecological benefits, the present situation of preventing and controlling soil and water loss is still severe.
\end{abstract}

Keywords: soil erosion, temporal-spatial changes, UAVRSS, Pisha-sandstone area

\section{Introduction}

Environmental problems present in the Loess Plateau ecosystem, such as vegetation destruction, soil degradation, water and soil loss, have become

*e-mail: qinyc@henu.edu.cn increasingly serious with an increase in global climate change. As a result, a series of social and economic problems have arisen, with ecological security in this area having widespread concern [1]. The Pisha sandstone area is widely distributed in the Yellow River watershed at the junction of Shanxi, Shaanxi, and Mongolia provinces. This area has been referred to as having "the world's most soil and water loss" and being termed as 
suffering from "environmental cancer" [2]. Although the Pisha sandstone area accounts for only $2 \%$ of the Loess Plateau, sediment discharged from this area accounts for $25 \%$ of the total sediment of the Yellow River. The volume of sediment lost from this area is having a serious impact on the implementation of sustainable development in this region. As part of China's Twelfth Five-Year Plan, erosion control was initiated in 2013 in the Pisha sandstone area. This investigation integrates previous soil and water conservation results in the area, evaluates the eco-environmental benefits obtained from an anti-erosion project, and provides a scientific basis for soil and water loss control planning.

Currently a wide number of theoretical and empirical investigations on soil erosion have been undertaken. Theoretical studies have resulted in the formulation of inherent driving mechanisms of soil erosion with the construction of a soil erosion model framework [3-4]. Investigations have also been undertaken analyzing the influential factors of soil erosion from a theoretical analysis [5-6], erosion assessment and prediction [7-11], soil erosion process simulation, and measures of anti-erosion and the promotion of plant growth [12-14]. Empirical research has also been used, for example to assess soil erosion on a watershed scale [15-16]. Taguas et al. [17] simulated the spatial distribution of water erosion using a sediment delivery distributed (SEDD) model across a small watershed in a Spanish olive orchard, and Elmouden et al. [18] evaluated spatial-temporal soil erosion in the Souss Massa River basin in Morocco.

Previous research on soil erosion in the Pisha sandstone area has focused on analysis of antierodibility [19], morphological characteristics [20], patterns of land use [21], and the evaluation of ecoenvironmental quality [22]. However, investigations have rarely analyzed the spatial-temporal evolution of soil erosion after the implementation of anti-erosion and the promotion of plant growth in this area. The majority of studies have focused on large- and medium-scale soil erosion, such as in the administrative area or in river basins [23-24]; small-scale studies on soil erosion have rarely been undertaken. As large- and mediumscale investigations on the differences of climate, hydrogeology, vegetation cover, and human activities on spatial heterogeneity of soil erosion only provide limited applicability, it is therefore important to examine smallscale soil erosion changes.

Unmanned aerial vehicle remote sensing system (UAVRSS) integrate unmanned aerial vehicles, remote sensing, radio communications, GPS differential positioning, and inertial measurement unit (IMU) inertial navigation and other technologies to quickly obtain information on a target object/area. Compared with traditional remote sensing technologies, UAV low-altitude remote sensing has significant advantages

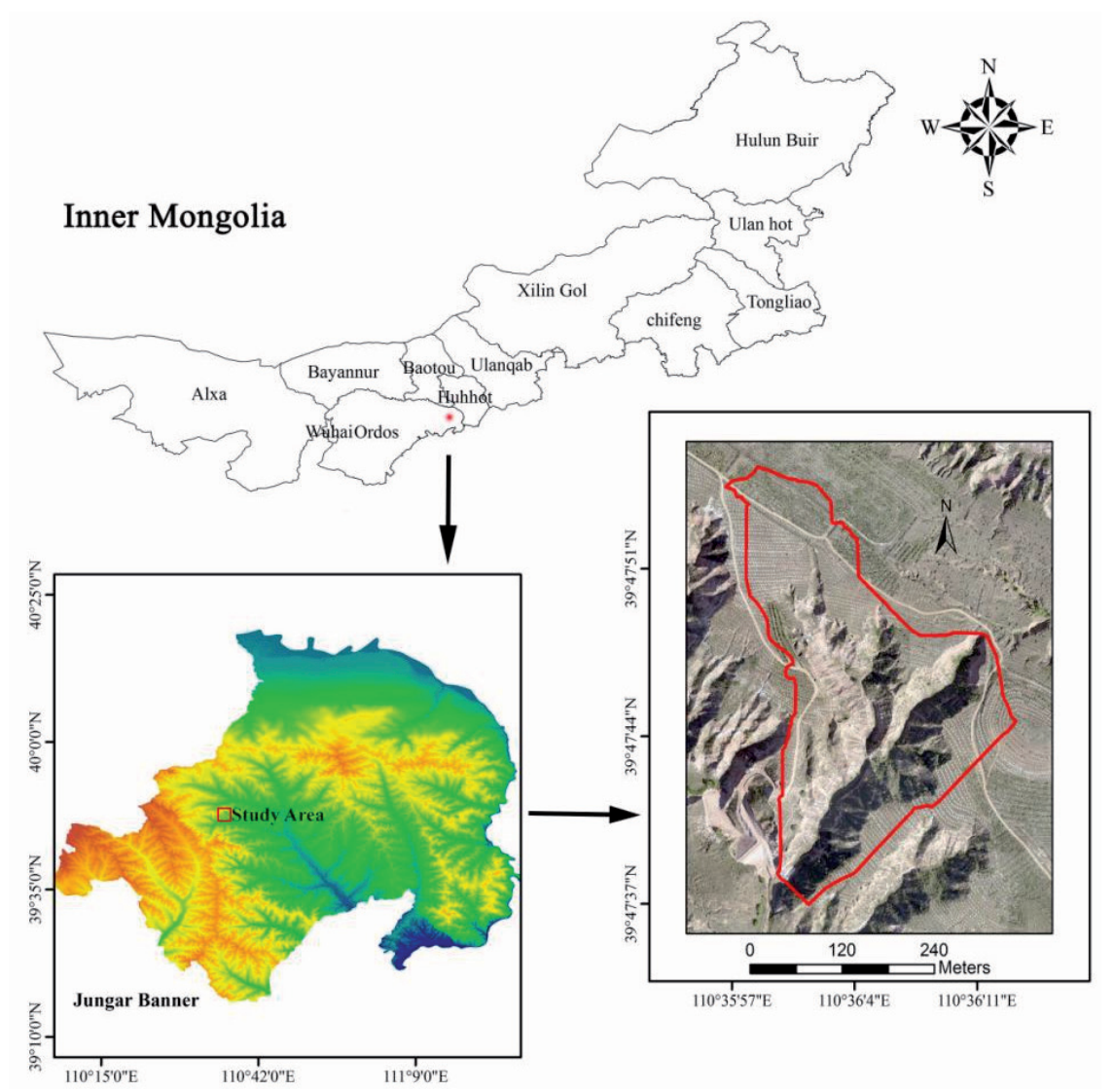

Fig. 1. UAV remote sensing image and geographical location of the study area. 

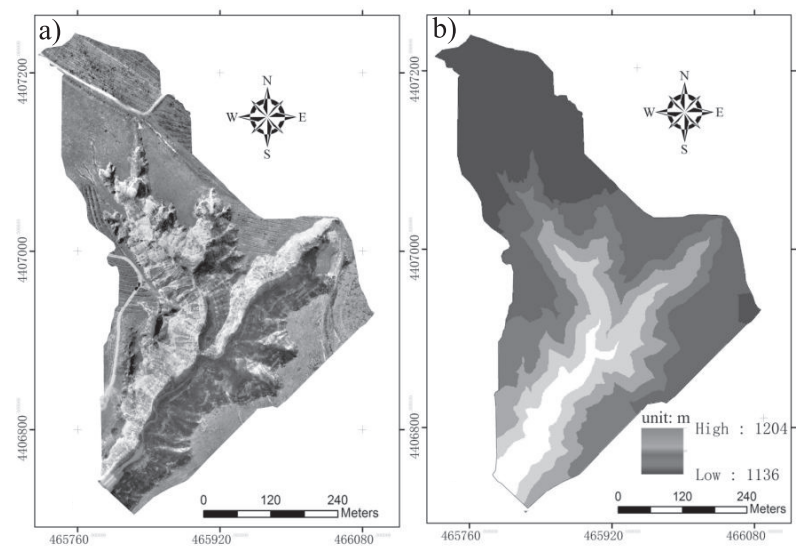

Fig. 2. Digital orthophoto map a) and digital elevation model b) of the study area, 2013.

in terms of spatial-temporal resolution, cloud impact, and economic cost [25]; this technique has seen an increase in use recently. UAVRSS is used in this study to evaluate the benefits of controlling soil erosion and obtaining high-resolution topography and image data in the study area. The revised universal soil loss equation is then used to evaluate the spatial-temporal evolution of soil erosion during the implementation of antierosion and the promotion of plant growth measures in a small-scale pattern. Results from this study will provide theoretical and technical support for managing soil and water conservation planning and comprehensive management in the Pisha sandstone area.

\section{Material and Methods}

\section{Study Area}

The Two-Tiger Valley Basin in the Pisha sandstone area $\left(39^{\circ} 47^{\prime} 37.48^{\prime \prime} \sim 39^{\circ} 47^{\prime} 54.92^{\prime \prime} \mathrm{N}\right.$, $110^{\circ} 35^{\prime} 58.9^{\prime \prime} \sim 110^{\circ} 36^{\prime} 14.84^{\prime \prime} \mathrm{E}$ ) (Fig. 1), located in Nuanshui town, Jungar Banner, Ordos, Inner Mongolia, is situated in the pilot area to examine plant growth as erosion control. This area has a typical arid and semi-arid continental climate, and has an annual flood season spanning June to September. The study area is fragmented and densely covered with ditches and valleys, many of which are deep and have V-shaped channels. The factors affecting soil erosion are normally water, wind, gravity, coverage, freeze-thaw, and properties of Pisha sandstone, etc., of which unsteadiness of stone is the most different factor from other areas. Relevant research [26] shows that Pisha sandstone is rich in extremely active components like $\mathrm{CaO}, \mathrm{K}_{2} \mathrm{O}$, and $\mathrm{Na}_{2} \mathrm{O}$. The properties of unsteadiness have led the area to be more vulnerable to external erosion and having the greatest impact on the local environment. The selected study area is believed to be representative for similar environments undergoing soil erosion, thus our results will be applicable in other areas.

\section{Data Resource}

Digital elevation model (DEM) (Fig. 2a), digital orthophoto map (DOM) (Fig. 2b), land use types, soil types, and daily precipitation data across the research area (2013 and 2015) were used in this study.

All data sources are shown in Table 1. All feature layers were converted into a Gaussian projection coordinate system to be a convenience to calculating, with a grid resolution of $1 \mathrm{~m}$.

\section{Methods}

The universal soil loss equation (USLE), first proposed by Wischmeier and Smith [27], can be used to predict annual average soil loss due to surface and gully erosion. The United States Department of Agriculture (USDA) improved the suitability of this equation to form a revised universal soil loss equation (RUSLE) [28]. In this study, the soil loss equation was calculated as:

$$
A=R \times K \times L \times S \times C \times P
$$

...where $A$ is the average annual soil erosion modulus $t \mathrm{~km}^{-2}$ year ${ }^{-1} ; R$ is the erosive factors for rainfallrunoff $M J \mathrm{~mm} \mathrm{~km}^{-2} \mathrm{~h}^{-1} \mathrm{year}^{-1} ; K$ is the soil erodibility factor $t \mathrm{~h} \mathrm{MJ}^{-1} \mathrm{~mm}^{-1}$; is the slope length factor;is the slope steepness factor; $C$ is the vegetation cover in the management factor; and $P$ is the soil and water conservation factor. Parameters $L, S, C$, and $P$ are all

Table. 1 Research data and sours.

\begin{tabular}{|c|c|c|}
\hline Data type & Directions & Data source \\
\hline DOM & $1: 1000$ UAV data & UAV remote sensing \\
\hline DEM & 1 m resolution DEM data & UAV remote sensing \\
\hline Meteorological data & daily rainfall data & Meteorological station \\
\hline Soil type data & $1: 1000$ soil type data & Visual interpretation and field research \\
\hline Land use type data & $1: 1000$ Land use type data & Visual interpretation and field research \\
\hline Basic geographic data & 30 m resolution DEM & National Earth Systems Science Data Sharing Infrastructure \\
\hline
\end{tabular}




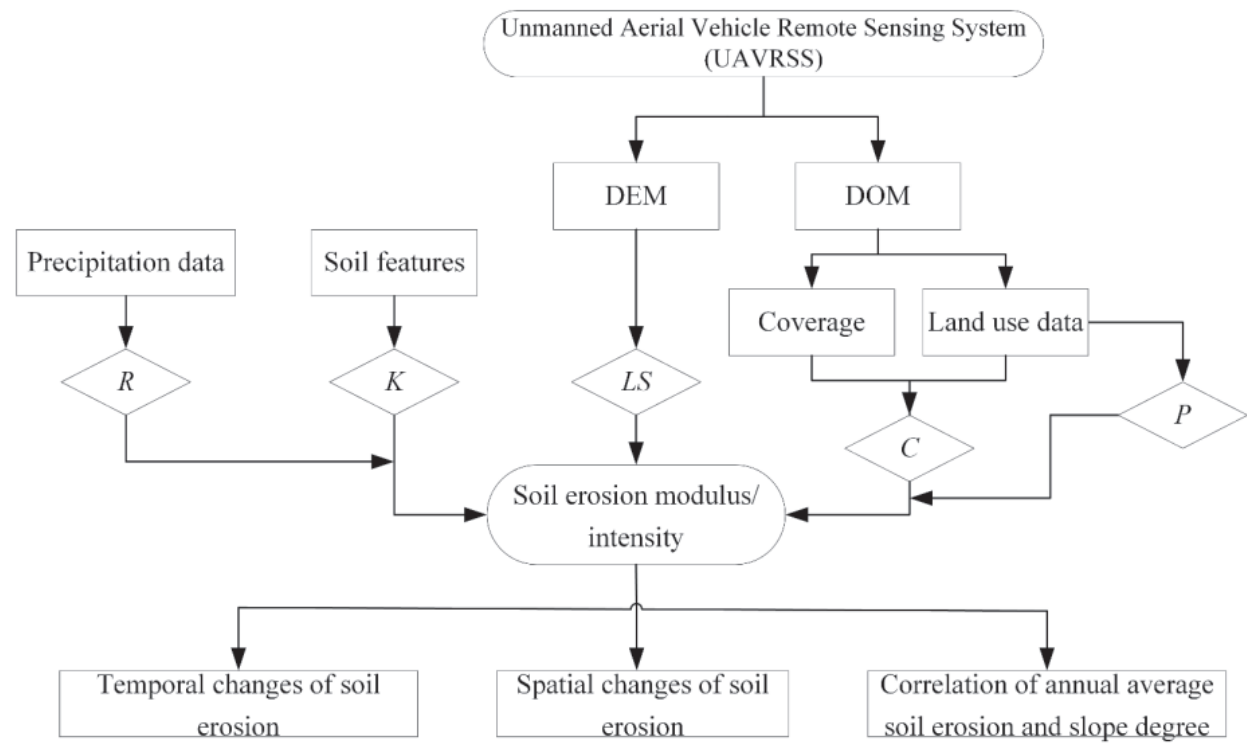

Fig. 3. The technical route of calculating soil erosion.

dimensionless. Fig. 3 is the flow chart of the entire methodology.

\section{Rainfall Erosivity Factor (R)}

The rainfall erosivity factor is the main dynamic factor resulting in soil erosion. Due to a lack of detailed data such as rainfall and intensity of rainfall, this study uses the calculation method of rainfall erosivity factor based on daily precipitation data proposed by Zhang et al. [29]. This method has been widely used to calculate erosion on the Yellow River Plateau due to a lack of detailed rainfall data. We chose daily rainfall greater than $12 \mathrm{~mm}$ as the valid values. The equations used are:

$$
\begin{gathered}
\mathrm{R}_{\text {Half }- \text { month }}=\alpha \sum_{k=1}^{m}\left(\mathrm{R}_{k}\right)^{\beta} \\
\beta=0.8363+\left(18.177 / P_{d 12}\right)+\left(24.455 / P_{y 12}\right) \\
\alpha=21.586 \beta^{-7.1891}
\end{gathered}
$$

...whereis $R_{k}$ the daily precipitation on the $k$ th day of the half month, and $P_{y 12}$ is the mean annual rainfall erosivity. The Half-month rainfall erosivity was calculated according to this equation and recorded as monthly rainfall erosivity. It should be noted that, due to the extremely small study area, the rainfall
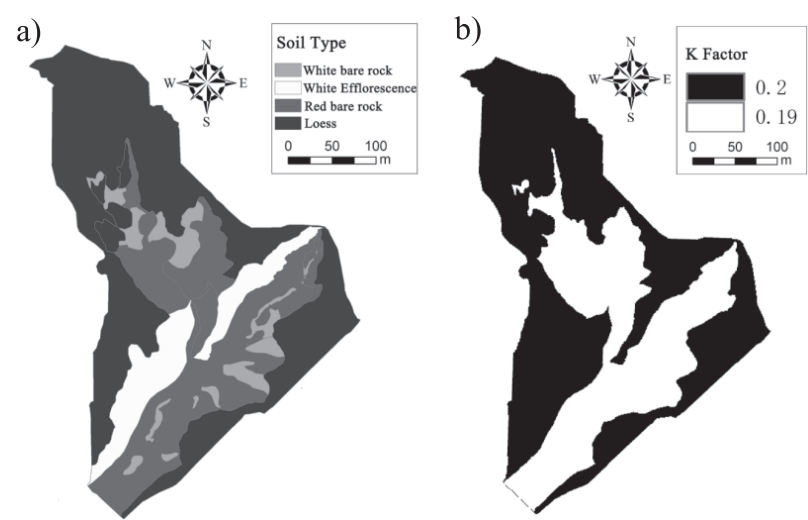

Fig. 4. Soil type a) and $K$ factor b) maps of the study area.

Table 2. Soil organic matter content and soil particle size distribution.

\begin{tabular}{|c|c|c|c|c|}
\hline Soil type & Soil organic matter & Coarse sand & Silt & Clay \\
\hline Pisha-sandstone (White bare rock) & 0.09 & 64.95 & 34.8 & 0.24 \\
\hline Slope wash (White) & 0.21 & 67.612 & 31.94 & 0.44 \\
\hline efflorescence (Red) & 0.18 & 55.94 & 43.78 & 0.28 \\
\hline Pisha sandstone (Red bare rock) & 0.11 & 54.47 & 45.35 & 0.19 \\
\hline Loess & 0.21 & 41.46 & 57.45 & 1.08 \\
\hline
\end{tabular}

Note: coarse sand: $50-2000 \mu \mathrm{m}$; silt: $2-50 \mu \mathrm{m}$; clay: 0.001-2 $\mu \mathrm{m}$ 
erosivity factor was calculated by daily precipitation data from a single station.

\section{Soil Erodibility Factor (K)}

The soil erodibility factor $(K)$ is affected by the inherent characteristics of the soil, with soil features mainly including: soil texture, structure, soil permeability, and clay mineral properties. In this study we used the erosion productivity impact calculator (EPIC) model. The $K$ value (Fig. 4b) was obtained using data for characteristics of the soil (Table 2) and soil type distribution (Fig. 4a) in the study area.

\section{Slope Steepness $(S)$ and Slope Length $(L)$}

Slope steepness and slope length are the basic geographical factors that reflect the impact of topography on soil erosion. Considering the actual situation of the study area, we used the calculation equation of the $L S$ factor in RUSLE to obtain the $L S$ factor for the whole study area (Fig. 5). The calculation equation was:

$$
\begin{aligned}
& \left\{\begin{array}{lc}
S=10.8 \times \sin \theta+0.03 & \theta<5^{\circ} \\
S=16.8 \times \sin \theta-0.05 & 5^{\circ} \leq \theta<14^{\circ} \\
S=21.91 \times \sin \theta-0.96 & \theta \geq 14^{\circ}
\end{array}\right. \\
& \mathrm{L}=(\lambda / 22.1)^{m} \mathrm{~m}=\left\{\begin{array}{cc}
0.2 & \left(\theta \leq 1^{\circ}\right) \\
0.3 & \left(1<\theta \leq 3^{\circ}\right) \\
0.4 & \left(3<\theta \leq 5^{\circ}\right) \\
0.5 & \left(\theta \geq 5^{\circ}\right)
\end{array}\right\}
\end{aligned}
$$

...where $\theta$ is the slope extracted by DEM $\left(^{\circ}\right) ; \lambda$ is the slope length extracted from DEM (m); $L$ is the slope length factor; $S$ is the slope steepness factor; and $m$ is the slope steepness and slope length index (the value of $m$ in study area being 0.5 ). According to results from the DEM, having a grid size of $1 \mathrm{~m}$, slope steepness and slope length factor were obtained by extracting the terrain parameters. Further details of this method can be found in Zhang et al. [30].

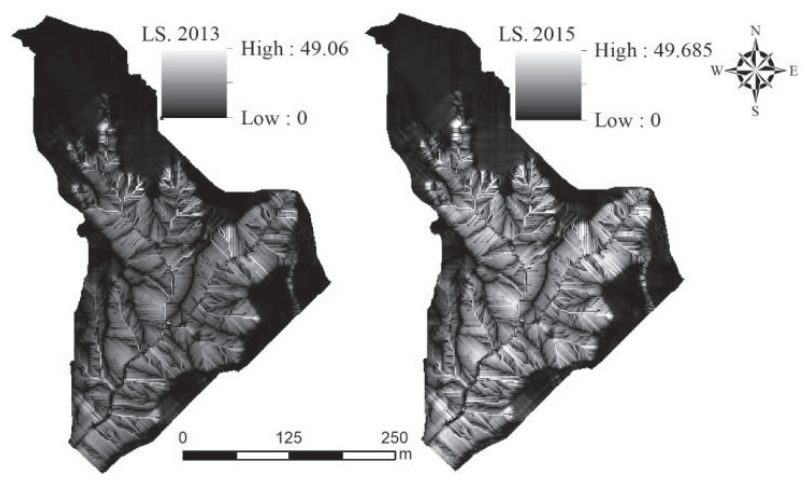

Fig. 5. LS factor maps of the study area in 2013 and 2015.

\section{Cover Management Factor (C)}

In this study, the vegetation distribution was initially interpreted before the vegetation data was divided into $1 \times 1 \mathrm{~m}$ grids. The proportion of vegetation in each grid was then calculated to provide vegetation coverage $f$ in 2013 and 2015 (Fig. 6a). The value of $C$ was calculated according to the following equation (Fig. 6b):

$$
C=\left\{\begin{array}{lc}
1 & 0 \leq f<0.1 \% \\
0.6508-0.3436 \times \lg (f) & 0.1 \% \leq f<78.3 \% \\
0 & f \geq 78.3 \%
\end{array}\right.
$$

\section{Soil and Water Conservation Support Practice Factor $(P)$}

The soil factor and water conservation measures reflect the impact of anti-erosion measures on soil. The results of this analysis range from 0 to 1 , with 0 indicating almost no erosion and 1 indicating soil erosion occurring due to no soil factor or water conservation measures having been implemented. According to the results of previous studies [31], the $P$ factors of the study area in 2013 and 2015 were determined based on

a)

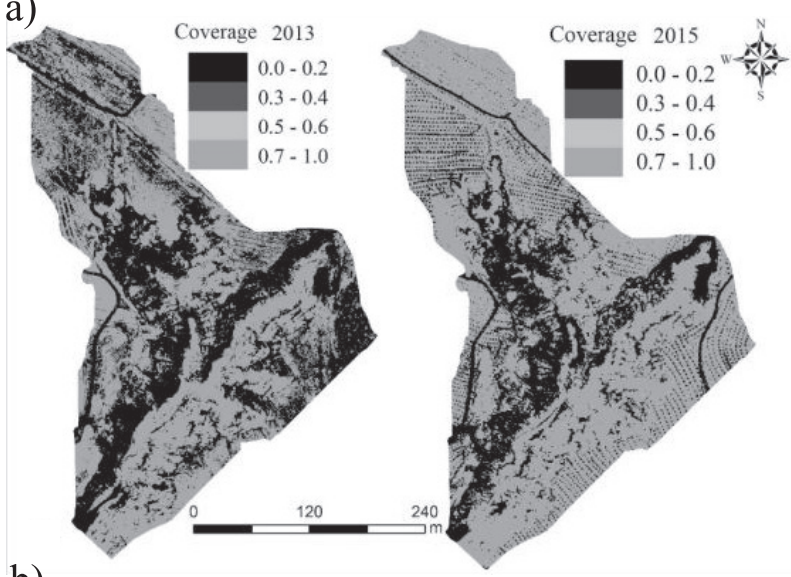

b)

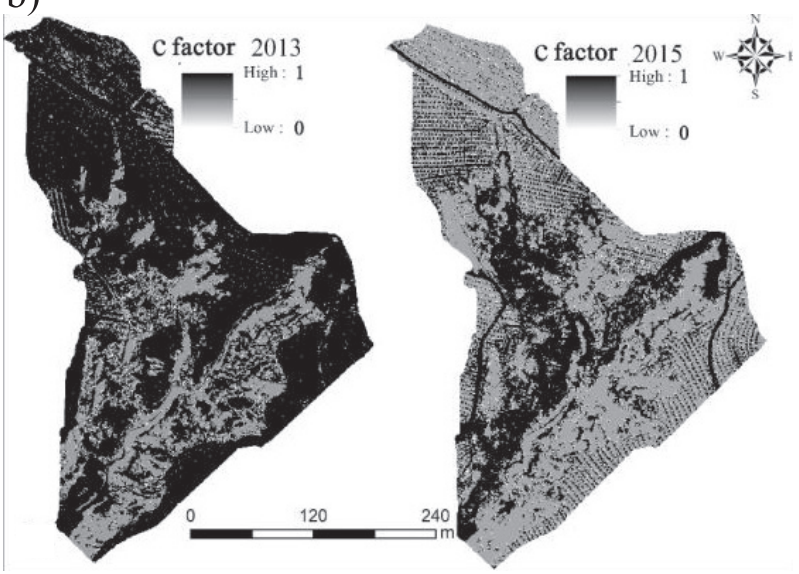

Fig. 6. Coverage a) and $\mathrm{C}$ factor b) maps of the study area in 2013 and 2015. 


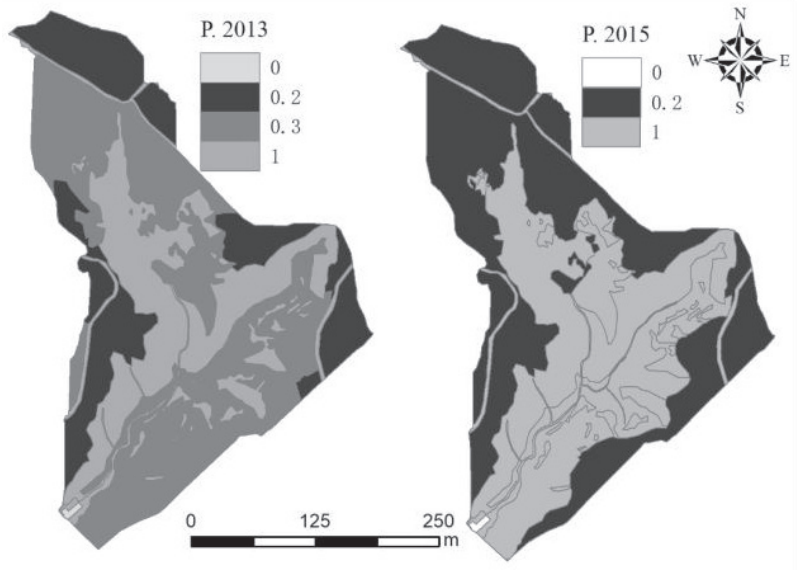

Fig. $7 P$ factor maps of the study area in 2013 and 2015.

the different conditions of land use in the study area (Fig. 7).

\section{Results and Discussion}

The RUSLE model was used to calculate the raster layer of each erosion factor in the study area and the raster calculator tool was used to multiply each soil erosion factor to obtain the pattern of soil erosion in 2013 and 2015. We quantitatively analyzed the interannual variation of the soil erosion modulus to evaluate positive influence of anti-erosion and the promotion of plant growth measures in the study area.

\section{Temporal Changes of Soil Erosion}

To investigate temporal changes in soil erosion intensity (between 2013 and 2015), we used standard "SL190-2007" [32] to divide the soil erosion modulus with the grid unit of $1 \times 1 \mathrm{~m}$ into six grades (microdegree to severe). The raster calculator tool in ArcGIS
10.4 was then used to calculate the distribution of erosion amount in 2013 and 2015 (Table 3).

Soil erosion intensity levels (Table 3) by 2015 had the order of: micro-erosion $(71.07 \%)$, moderate erosion $(11.65 \%)$, mild erosion (9.99\%), intense erosion (5.93 $\%$, very intensive erosion (1.24\%), and severe erosion (0.1\%). Between 2013 to 2015 the soil erosion amounts of micro-erosion decreased by $3.65 \mathrm{t}$ (from 14.24 to 10.58). The soil erosion modulus of micro-degree and mild erosion decreased from $212.82 \mathrm{t} \mathrm{km}^{-2}$ year $^{-1}$ and $1642.51 \mathrm{t} \mathrm{km}^{-2}$ year $^{-1}$ to $154.95 \mathrm{t} \mathrm{km}^{-2}$ year $^{-1}$ and 1648.54 $\mathrm{t} \mathrm{km}^{-2}$ year ${ }^{-1}$, and the soil erosion modulus of microerosion erosion decreased by $27.19 \%$. The soil erosion amounts of mild erosion and micro-erosion decreased $6.82 \mathrm{t} \mathrm{year}^{-1}$ from 2013 to 2015. Soil erosion modulus showed a decreasing trend, indicating that soil erosion in the study area was effectively controlled and the ecological environment significantly improved. This result is in accordance with soil erosion findings by Wang et al. [33] on the Loess Plateau.

The soil erosion modulus of moderate and strong erosion levels recorded only a slight change between 2013 and 2015. The soil erosion amounts of moderate and severe erosion levels in 2015 were 41.31 t year $^{-1}$ and $34.85 \mathrm{t} \mathrm{year}^{-1}$, the total proportion of two levels increased by $66.40 \%$, this recording the most severe soil erosion in the study area. The phenomenon appeared due to not being suitable for use and being locating in the wasteland area. This area has a broad steep slope and experiences severe gravity erosion. In addition, although biological measures have been implemented, due to the wide area of undeveloped forest the ecological and environmental benefits have not been fully exerted. Therefore, the moderate and intense erosion levels should be viewed as key areas for subsequent projects to reduce anti-erosion and promote engineering solutions. In 2015, the soil erosion modulus of extremely intense erosion and severe erosion were $10269.78 \mathrm{t} \mathrm{km}^{-2}$ year $^{-1}$ and $16322.98 \mathrm{t} \mathrm{km}^{-2}$ year ${ }^{-1}$, respectively, this being more

Table 3. Distribution of soil erosion intensity levels in 2013 and 2015

\begin{tabular}{|c|c|c|c|c|c|c|c|c|}
\hline \multirow{2}{*}{$\begin{array}{l}\text { Soil erosion } \\
\text { modulus } \\
/ \mathrm{t} \mathrm{km}^{-2} \mathrm{year}^{-1}\end{array}$} & \multirow[b]{2}{*}{$\begin{array}{l}\text { Erosion } \\
\text { degree }\end{array}$} & \multicolumn{3}{|c|}{2013} & \multicolumn{3}{|c|}{2015} & \multirow{2}{*}{$\begin{array}{c}2013-2015 \\
\text { Variation of } \\
\text { soil erosion } \\
\quad / \mathrm{t} \mathrm{km}^{-2}\end{array}$} \\
\hline & & $\begin{array}{c}\text { Erosion } \\
\text { area } / \mathrm{km}^{2}\end{array}$ & $\begin{array}{l}\text { Soil erosion } \\
\text { modulus } \\
/ \mathrm{t} \mathrm{km}^{-2} \mathrm{year}^{-1}\end{array}$ & $\begin{array}{l}\text { Total erosion } \\
/ \mathrm{t} \mathrm{km}^{-2}\end{array}$ & $\begin{array}{c}\text { Erosion } \\
\text { area } / \mathrm{km}^{2}\end{array}$ & $\begin{array}{l}\text { Soil erosion } \\
\text { modulus } \\
/ \mathrm{t} \mathrm{km}^{-2} \mathrm{year}^{-1}\end{array}$ & $\begin{array}{l}\text { Total ero- } \\
\text { sion } \\
/ \mathrm{t} \mathrm{km}^{-2}\end{array}$ & \\
\hline $0 \sim 1000$ & micro & 0.0669 & 212.82 & 14.24 & 0.0683 & 154.95 & 10.58 & -3.65 \\
\hline $1000 \sim 2500$ & mild & 0.0104 & 1642.51 & 17.08 & 0.0096 & 1448.54 & 13.91 & -3.17 \\
\hline $2500 \sim 5000$ & moderate & 0.0114 & 3677.74 & 41.93 & 0.0112 & 3688.79 & 41.31 & -0.61 \\
\hline $5000 \sim 8000$ & intense & 0.0059 & 6124.55 & 36.13 & 0.0057 & 6114.10 & 34.85 & -1.28 \\
\hline $8000 \sim 15000$ & extreme & 0.0013 & 10357.48 & 13.46 & 0.0012 & 10269.78 & 12.32 & -1.14 \\
\hline$>15000$ & severe & 0.0002 & 16989.49 & 3.40 & 0.0001 & 16322.98 & 1.63 & -1.77 \\
\hline
\end{tabular}

Note: Soil erosion classification grading standard: micro-erosion: $<1000 \mathrm{t} \mathrm{km}^{-2} \mathrm{year}^{-1}$; mild erosion: 1000-2500 $\mathrm{t} \mathrm{km}^{-2} \mathrm{year}^{-1}$; moderate erosion: 2500-5000 t km${ }^{-2}$ year-1; intense erosion: 5000-8000 t km${ }^{-2}$ year ${ }^{-1}$; very extreme erosion: 8000-15000 $\mathrm{t} \mathrm{km}^{-2}$ year ${ }^{-1}$; severe erosion: $>15000 \mathrm{t} \mathrm{km}^{-2}$ year $^{-1}$ 


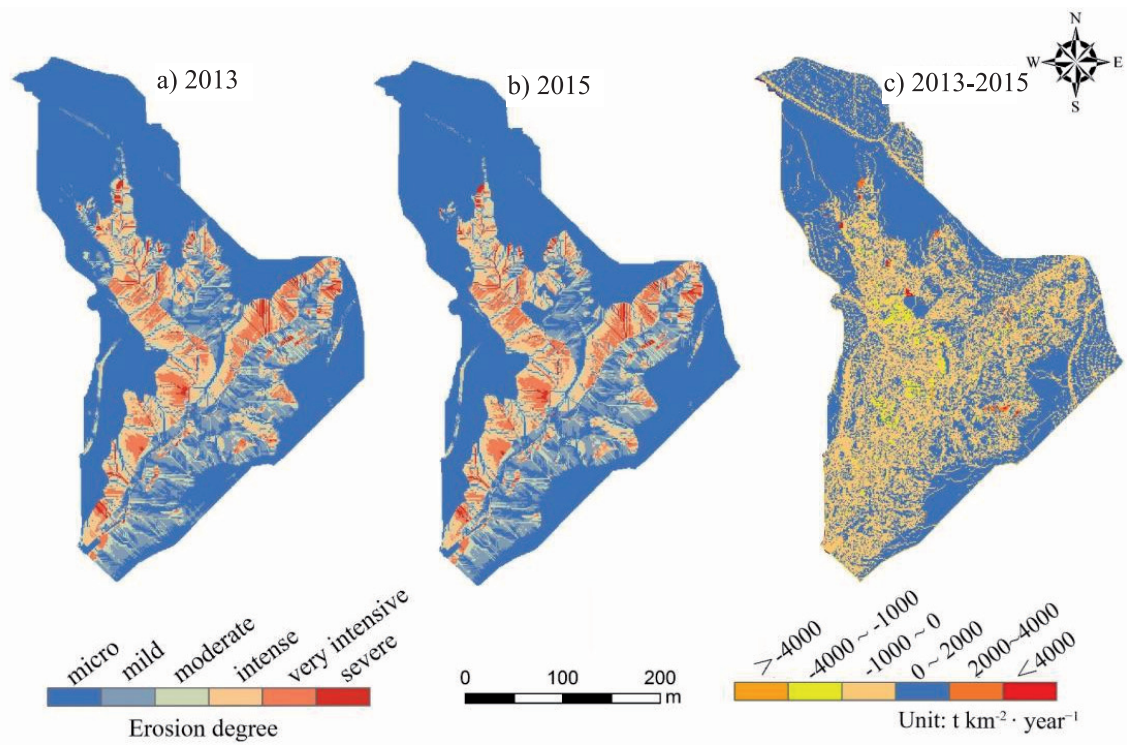

Fig. 8. Soil erosion grade and spatial change across the study area.

than 10-times greater than the allowable soil erosion modulus $\left(1000 \mathrm{t} \mathrm{km}^{-2}\right.$ year $\left.^{-1}\right)$. However, the amount of soil erosion was much lower than that recorded at the moderate and intense erosion levels due to being maintained at $1 \%$. In addition, it should be noted that the average modulus of soil erosion in 2015 was as high as $6333.19 \mathrm{t} \mathrm{km}^{-2}$ year $^{-1}$, and that the severe erosion modulus was $16322.98 .11 \mathrm{t} \mathrm{km}^{-2}$ year $^{-1}$ - both results being significantly higher than the permissible value of soil erosion (1000 t km$~^{-2}$ year $^{-1}$ for the northwest Loess Plateau; Ministry of Water Resources PRC, 2008).

These results indicate that annual soil erosion significantly decreased in the study area from 2013 to 2015. The results also show that the soil erosion modulus for all grades decreased to some extent, indicating that as parts of China's Twelfth FiveYear Plan the implementation of the anti-erosion and promotion of plant growth achieved a certain degree of ecological and environmental success, and that soil and water loss prevention and treatment has progressed. At the same time, due to the significant base of water and soil loss, the current situation of soil and water loss was still extreme and that the ecological environment is still very fragile. The positive impact of controlling soil and water loss in small watersheds of the Pisha sandstone area has some degree of finiteness, and the anti-erosion and promotion of plant growth is a long process.

\section{Spatial Changes of Soil Erosion}

Based on the six degrees of soil erosion, the spatial pattern of soil erosion changes in the study area were plotted and analyzed to identify any noticeable characteristics (Fig. 8). Results from this analysis show that soil erosion levels in the loess-covered area around the study area mainly consisted of mild and moderate erosion levels (Fig. 8 a and b), and that soil erosion levels mainly consisted of micro-erosion by 2015. This change in erosion levels indicated that the anti-erosion and promotion of plant growth measures extenuated the soil erosion conditions around the study area, and that the ecological environment improved to a certain extent. The reason for this change is due to the prevention and control of soil and water erosion, and to the restoration of vegetation (which mainly included Seabuckthorn and Mongolian pomfret). As a result, the area of land use pattern also had a dramatic change. The area of bare sandstone and sandy land decreased, and the proportion of grassland and shrubland increased sharply. In addition, eco-immigrants returned farmland to forests and grasslands within the basin, which was also an important factor for ecological restoration. Results for soil erosion levels (Fig. 8c) showed a gradual increase from the periphery to the center from 2013 to 2015. The soil erosion modulus around the study area decreased, and only partially improved in the central area $\left(>2000 \mathrm{t} \mathrm{km}^{-2}\right.$ year $\left.{ }^{-1}\right)$. The majority of areas maintained their original status $\left(-4000 \sim-1000 \mathrm{t} \mathrm{km}^{-2}\right.$ year ${ }^{-1}$ ), or became worse, indicating that the biological measures undertaken were not very effective in controlling soil and water loss in these areas.

The spatial pattern of soil erosion in the study area from 2013 to 2015 followed the trend of a rapid increase from the periphery to the center. A decrease was recorded for the periphery of the study area and it was basically unchanged in the central region. There are plural reasons for the significant spatial heterogeneity of soil erosion. Compared with the central area, the area surrounding the study area is covered by a few meters of loess with flat ground and suitable conditions for vegetation growth. However, the central area has many V-shaped valleys and the slope of this region has numerous changes, thus resulting in the bio-engineering measures not succeeding. In addition, 
the combination of water and gravity erosion further aggravates soil erosion, indicating that the benefits of biological measures to control soil erosion have spatial heterogeneity. Our results suggest that the local population should take a variety of prevention measures according to the different local conditions. Finally, Seabuckthorn-based anti-erosion measures were applied in the loess area around the study area. This measure has played an effective role in protecting the soil and significantly reducing soil and water loss in some areas.

\section{Correlation of Annual Average Soil Erosion and Slope Degree}

As soil erosion from different slopes has a wide variety, identifying the correlation between slope and erosion modulus is very important for the area of antierosion. Because it can help us identify the areas with severe soil erosion and make appropriate measures for soil and water conservation in areas with large changes in slope. Soil erosion at different slope grades (annual average slope degree) was calculated by DEM and soil erosion data in the study area. The average slopes of 2013 and 2015 were then divided into six levels using the reclassification tool. Finally, based on the average soil erosion and slope data in 2013 and 2015, the soil erosion modulus at different slopes was obtained using zonal statistical methods (Table 4).

Annual average soil erosion modulus at different slope degrees is shown in Table 4. Results indicate that the area of slope $<5^{\circ}$ occupies $29.2 \%$ of the total study area, and that the area having a slope $>25^{\circ}$ accounts for $48.1 \%$, a result that shows that the gradient of the ground surface changes dramatically. The reason for this dramatic change is due to the surface of the study area being subject to perennial hydraulics, gravity, and wind erosion. In addition, the intrinsic rigidity of the Pisha sandstone and the large area of exposed rock are also important reasons for surface crushing. Analysis of the relationship between slope and soil erosion in the study area shows that:

1) Micro-erosion is present at $0<$ slope $<15^{\circ}$; mild erosion is present at $15^{\circ}<$ slope $<35^{\circ}$; and slopes $>35^{\circ}$ show moderate levels of erosion. The degree of soil erosion at each slope level is at or below moderate erosion levels, indicating an improvement of soil erosion to some extent. This result is due to the implementation of prevention and control measures for soil and water loss, combined with the reduction of human activities in the area and the improvement of the environmental quality caused by local populations moving to cities.

2) Although the area with $0<$ slope $<15^{\circ}$ accounts for $45.6 \%$ of the whole study area, soil erosion amount is only $5.4 \mathrm{t}^{\mathrm{year}}{ }^{-1}$, this being $0.49 \%$ of total erosion. This finding is a product of the most obvious ecological and environmental benefits of soil and water conservation measures.

3) When $15^{\circ}<$ slope $<25^{\circ}$, the modulus of soil erosion accounting for $1024.615 \mathrm{~km}^{-2}$ year ${ }^{-1}$, accounted for $17.32 \%$ of the total area. The degree and scale of soil erosion gradually increased.

4) The modulus of soil erosion for slopes $>25^{\circ}$ accounted for $73.44 \%$ of the whole area, with soil erosion accounting for more than $90 \%$ of the whole area. This finding shows that this slope degree is the area where soil erosion is the most concentrated.

5) The modulus of soil erosion for slopes $>35^{\circ}$ is as high as $2574.413 \mathrm{t} \mathrm{km}^{-2}$ year ${ }^{-1}$, accounting for $43.52 \%$ of total erosion. Soil erosion attains its peak value at this slope degree, indicating this is where the most drastic soil erosion occurs. These results show that with an increase in slope degree, soil erosion modulus also increases. A significant positive correlation between slope and soil erosion modulus exists. In addition, the spatial change pattern of slope degree in the study area from 2013 to 2015 followed a decrease trend in the periphery and it was basically unchanged or slightly increased in the central region. The slope grew by an average of $0.74^{\circ}$ in the study area from 2013 to 2015 . The slope changes mainly concentrated on the degree of $15-25^{\circ}$ and $25-35^{\circ}$, and the variation of slope degree was $2.08^{\circ}$ and $1.81^{\circ}$, respectively. It is shown that the slope factor is the main factor affecting soil erosion in the Two-Tiger Valley watershed. This conclusion is similar to the conclusion drawn by related scholars on soil erosion in the Loess Plateau. Therefore the formulation of control strategies for soil erosion in

Table 4. Soil erosion modulus on different slopes in the study area.

\begin{tabular}{|c|c|c|c|c|c|c|}
\hline Slope degree & $\begin{array}{l}\text { Area } \\
/ \mathrm{km}^{2}\end{array}$ & $\begin{array}{l}\text { Erosion modulus } \\
\qquad /\left[\mathrm{t} / \mathrm{km}^{2} \cdot \mathrm{a}\right]\end{array}$ & $\begin{array}{c}\text { Erosion modulus ratio } \\
(\%)\end{array}$ & $\begin{array}{c}\text { Erosion amount } \\
{[\mathrm{t} / \mathrm{a}]}\end{array}$ & $\begin{array}{c}\text { Erosion amount ratio } \\
(\%)\end{array}$ & Erosion degree \\
\hline $0-5^{\circ}$ & 0.028 & 51.355 & 0.87 & 1.44 & 0.13 & micro-degree \\
\hline $5-8^{\circ}$ & 0.008 & 118.771 & 2.01 & 0.95 & 0.09 & micro-degree \\
\hline $8-15^{\circ}$ & 0.008 & 376.622 & 6.37 & 3.01 & 0.27 & micro-degree \\
\hline $15-25^{\circ}$ & 0.006 & 1024.615 & 17.32 & 6.15 & 0.55 & mild \\
\hline $25-35^{\circ}$ & 0.115 & 1769.659 & 29.92 & 203.51 & 18.32 & mild \\
\hline$>35^{\circ}$ & 0.348 & 2574.413 & 43.52 & 895.90 & 80.64 & moderate \\
\hline
\end{tabular}


the Pisha-sandstone area must take full account of the gradient factor of topography.

\section{Conclusions}

This investigation analyzed the spatial-temporal evolution of soil erosion and revealed a correlation between soil erosion and slope factors in the Two-Tiger Valley in the Pisha sandstone region, with the following main conclusions:

1) Results from this study showed an obvious temporalspatial variation of soil erosion between 2013 and 2015 in the Pisha sandstone area, Loess Plateau, China. Results for the spatial analysis showed the modulus of soil erosion around the study area to gradually decrease while the central area remained unchanged. This finding demonstrated that the positive effect of the anti-erosion and the promotion of plant growth measures had a strong spatial difference. Temporal results, in addition to the extreme erosion recorded at the site, showed different degrees of soil erosion reduction over time. Compared with 2013, soil erosion modulus and erosion levels in 2015 were generally lower, indicating that the antierosion and the promotion of plant growth measures was beneficial to soil and water conservation.

2) The series of biological and engineering measures from 2013 to 2015 resulted in a significant increase of surface vegetation coverage in the study area and subsequently an improvement in the regional ecological environment. However, it should be stressed that the average modulus of soil erosion was still as high as $6499.86 \mathrm{t} \mathrm{km}^{-2}$ year $^{-1}$ in 2015 - far beyond the limits of soil erosion permitted by the state. The proportion of moderate and intense erosion attained $66.40 \%$, with soil erosion being the dominant process in the Two-Tiger Valley watershed.

3) There was a significant positive correlation between slope degree and soil erosion modulus. When the slope degree was $>25^{\circ}$, the soil erosion level was moderately eroded and the modulus of soil erosion accounted for $73.44 \%$ of the total area. Thus, the interval of slope $>25^{\circ}$ was the area with the most soil and water loss, this being dominated by gravity erosion. These areas are important for future antierosion and the promotion of plant growth measures. In addition, soil erosion control should include topographic factors, with soil and water conservation strategies developed in close consideration of local conditions.

\section{Acknowledgements}

The authors thanks Mr, Fen Qin team for their assistance in collecting the UAV remote sensing data for this study. Special thanks National Science \& Technology Infrastructure of China, Data Sharing
Infrastructure of Earth System Science -Data Center of Lower Yellow River Regions (http://henu.geodata.cn). This research was supported by National Natural Science Foundation of China (No.41671536; No.41501588).

\section{References}

1. ZHAO G., MU X., WEN Z., WANG F., GAO P. Soil erosion, conservation and eco-environmental changes in the Loess Plateau of China, Land Degradation and Development. 24 (5), 499, 2013.

2. WANG Y., WU Y., KOU Q., MIN D., CHANG Y., ZHANG R. Definition of arsenic rock zone borderline and its classification, Science of Soil and Water Conservation. 5 (1), 14, 2007.

3. MORGAN R.P.C., QUINTON J.N., SMITH R.E., GOVERS G., POESEN J.W.A., AUERSWALD K. The European soil erosion model (EUROSEM): A dynamic approach for predicting sediment transport from fields and small catchment, Earth Surface Processes and Landforms. 23 (6), 527, 2015.

4. MONDAL A., KHARE D., KUNDU S. A comparative study of soil erosion modelling by MMF, USLE and RUSLE. Geocarto International, 2016.

5. XI J., ZHAO X., WANG X., ZHANG Z. Assessing the impact of land use change on soil erosion on the Loess Plateau of China from the end of the 1980s to 2010. Journal of Soil and Water Conservation. 72 (5), 452, 2017.

6. BAGYARAJM., RAMKUMAR T., VENKATRAMANAN S., CHUNG S. Y. GURUGNANAM B. Assessment of soil erosion probability in Kodaikanal, India using GIS and remote sensing. Disaster Advances. 7 (2), 36, 2014.

7. NOORI H., KARAMI H., FARZIN S., SIADATMOUSAVI S. M., MOJARADI B., KISI O. Investigation of RS and GIS techniques on MPSIAC model to estimate soil erosion. Natural Hazards Journal of the International Society for the Prevention and Mitigation of Natural Hazards. 91 (1), 221, 2018.

8. VIJITH H., REKHA V.B., SHIJU C., REJITH P.G. An assessment of soil erosion probability and erosion rate in a tropical mountainous watershed using remote sensing and GIS, Arabian Journal of Geosciences. 5 (4), 797, 2012.

9. JEMBERU W., BAARTMAN J., FLESKENS L., RITSEMA C.J. Participatory assessment of soil erosion severity and performance of mitigation measures using stakeholder workshops in Koga catchment, Ethiopia. Journal of Environmental Management. 207 (230), 230, 2018.

10. HANCOCK G.R., VERDONKIDD D., JBC L. Soil erosion predictions from a landscape evolution model - An assessment of a post-mining landform using spatial climate change analogues. Science of the Total Environment, 601, 109, 2017.

11. YU M., HUANG Y., SUN C.F., WU Y. Spatial-Temporal Analysis of Soil Erosion in Ninghua County Based on the RUSLE, Springer Singapore, 2017.

12. TAMENE L., ADIMASSU Z., ELLISON J., YAEKOB T., WOLDEAREGAY K., MEKONNEN K., THORNEF P., LE B. Mapping soil erosion hotspots and assessing the potential impacts of land management practices in the highlands of Ethiopia. Geomorphology, 2017.

13. SINHA N., DEB D., PATHAK K. Development of a mining landscape and assessment of its soil erosion potential using GIS. Engineering Geology. 1, 2016. 
14. OBAID H.A., SHAHID S. Soil erosion susceptibility of Johor River basin. Water and Environment Journal, 2017.

15. ZARE M., SAMANI A.A.N., MOHAMMADY M., TEIMURIAN T., BAZRAFSHAN J. Simulation of soil erosion under the influence of climate change scenarios. Environmental Earth Sciences, 75 (21), 1405, 2016.

16. GANASRI B.P., RAMESH. Assessment of soil erosion by RUSLE model using remote sensing and GIS - A case study of Nethravathi Basin. Geoscience Frontiers, 7 (6), 953, 2016.

17. TAGUAS E.V., MORAL C., AYUSO J.L., PÉREZ R., GÓMEZ J.A. Modelling the spatial distribution of water erosion within a Spanish olive orchard microcatchment using the SEDD model, Geomorphology, 133 (2), 47, 2011.

18. ELMOUDEN A., ALAHIANE N., FASKAOUI M.E., MORJANI Z.E.A.E. Dams Siltation and Soil Erosion in the Souss-Massa River Basin. Morocco. Springer, Cham. 95, 2016

19. LI X.Y., YUE G.F., RAN S.U., JUAN Y.U. Research on Pisha-sandstone's anti-erodibility based on grey multilevel comprehensive evaluation method. Journal of Groundwater Science and Engineering. 4 (2), 103, 2016.

20. ZHANG C.C., QIN F., WANG H., LI N., LI Y. Quantization and Spatial Variation of Topographic Features Using 3D Fractal Dimensions in Arsenic Rock Area, Scientia Geographica Sinica. 36 (1), 142, 2016.

21. SHENG Y., QIN F.C., ZHANG Y.J. Study on Land-use Change and Pattern Optimization of Small Watershed in Soft Rock Region, Research of Soil and Water Conservation. 21 (2), 76, 2014.

22. YAO J.N., QIN F. Comprehensive assessment on Ecoenvironmental quality of the area of sandstone, Research of Soil and Water Conservation. 21 (6), 193, 2014.

23. YE J.D., QIN F.C., YUE Y.J., ZHANG Y. The applicability of WEPP in simulating the soil erosion in soft rock region, Journal of Arid Land Resources and Environment. 26 (7), 132, 2012.
24. CORREA S.W., MELlO C.R., CHOU S.C., CURI N., NORTON L.D. Soil erosion risk associated with climate change at Mantaro River basin, Peruvian Andes. Catena. 147, 110, 2016.

25. LIU X., CHEN P., TONG X., LIU S., LIU S.J., HONG Z.H., LI L.Y., LUAN K.F. UAV-based low-altitude aerial photogrammetric application in mine areas measurement, 2012 Second International Workshop on Earth Observation and Remote Sensing Applications (EORSA), 240, 2012.

26. LI X.Y., YUE G.F., RAN S.U., YU J. Research on Pishasandstone's anti-erodibility based on grey multi-level comprehensive evaluation method. Journal of Groundwater Science and Engineering, 4 (2), 103, 2016.

27. WISCHMEIER W.H., SMITH D.D. Predicting rainfall erosion losses - a guide to conservation planning. United States. dept. of Agriculture. agriculture Handbook, 1978.

28. RENARD K.G., FOSTER G.R., WEESIES G.A., PORTER J.P. RUSLE: Revised universal soil loss equation, Journal of soil and Water Conservation. 46 (1), 30, 1991.

29. ZHANG W.B., XIE Y., LIU B.Y. Rainfall erosivity estimation using daily rainfall amounts, Scientia Geographica Sinica. 22 (6), 705, 2002.

30. ZHANG H., YANG Q., LI R., LIU Q., MOORE D., HE P. Extension of a GIS procedure for calculating the RUSLE equation ls factor, Computers and Geosciences. 52 (1), 177, 2013.

31. YU F., LI X. B., HAO C.Y., CHEN Y.H., WANG H., YANG M.H. Land use change and soil erosion evaluation in Huangfuchuan Watershed, Acta Ecologica Sinica, 26 (6), 1947, 2006

32. THE MINISTRY OF WATER RESOURCES PRC. SL1902007, Standards for classification and Gradation of Soil Erosion, Beijing: China Water Power Press, 2008.

33. WANG J., ZHUO J. Quantitative Assessment of Soil Erosion in Areas Under Grain for Green Project in Loess Plateau of Northern Shaanxi Province Based on GIS and RS. Bulletin of Soil and Water Conservation, 35 (1), 220, 2015. 